\title{
The impact of antipsychotic drugs on food intake and body weight and on leptin levels in blood and hypothalamic ob-r leptin receptor expression in wistar rats
}

\author{
Martina von Wilmsdorff,' Marie-Luise Bouvier,' Uwe Henning,' Andrea Schmitt, II,III Wolfgang Gaebel' \\ 'LVR Klinikum Düsseldorf, Kliniken der Heinrich-Heine-Universität, Düsseldorf, Germany. "Department of Psychiatry, University of Göttingen, Göttingen, \\ Germany. "'Laboratory of Neuroscience (LIM27), Institute of Psychiatry, Faculdade de Medicina, Universidade de São Paulo, SP, Brazil.
}

OBJECTIVES: The aim of our study was to investigate the impact of typical and atypical antipsychotic drugs on leptin concentration in blood and changes in the receptor expression in the hypothalamus of male Wistar rats.

METHODS: From the age of 13 to 18 weeks, three groups of 20 animals were fed an average dose of $3.5 \pm 0.03$ $\mathrm{mg} / \mathrm{kg}$ body weight (BW) haloperidol; $30.6 \pm 0.22 \mathrm{mg} / \mathrm{kg} \mathrm{BW}$ clozapine; or $14.9 \pm 0.13 \mathrm{mg} / \mathrm{kg}$ BW ziprasidone in ground food pellets containing $15 \%$ fat. Twenty control animals received no drugs. Blood samples were taken at week 14, 16, and 19. Locomotor activity and exploratory behavior were measured using the alcove test at weeks 15 and 17. The expression of the hypothalamic leptin receptor in rat brains was determined by using a Western blot.

RESULTS: Rats medicated with haloperidol and ziprasidone showed a significantly decreased percentage weight gain and food consumption. We observed no differences in the alcove test, but locomotor activity was significantly reduced in the haloperidol group. Except for rats in the clozapine and ziprasidone groups, after 2 weeks of drug application, we found no changes in the leptin blood concentrations among the four groups or animals within each group. Moreover, we did not find specific differences in hypothalamic leptin receptor expression among the groups.

CONCLUSION: We concluded that in male Wistar rats during this treatment period, the tested drugs did not act directly on the leptin regulatory system. We recommend further studies using long-term treatment of different rat strains.

KEYWORDS: Schizophrenia; Haloperidol; Clozapine; Ziprasidone; Leptin; Leptin receptor.

von Wilmsdorff M, Bouvier ML, Henning U, Schmitt A, Gaebel W The impact of antipsychotic drugs on food intake and body weight and on leptin levels in blood and hypothalamic ob-r leptin receptor expression in wistar rats. Clinics. 2010;65(9):885-894.

Received for publication on June 15, 2010; First review completed on June 15, 2010; Accepted for publication on June 22, 2010

E-mail: aschmit@gwdg.de

Tel.: 495513910366

\section{INTRODUCTION}

Antipsychotic drug medication is an important therapeutic option for the treatment of patients suffering from schizophrenia and other psychoses. Based on their mechanism of action, antipsychotics are classified as either typical or atypical drugs. Medication with typical antipsychotic drugs (haloperidol is applied most frequently) can be accompanied by severe extrapyramidal side effects. Atypical antipsychotic drugs like clozapine usually cause no extrapyramidal side effects but can lead to unwanted weight gain. ${ }^{1,2}$ Interestingly, ziprasidone, a newer atypical antipsychotic drug, is not linked with weight gain. ${ }^{3}$ As increased body weight may be associated with an increase in blood leptin concentration, ${ }^{4}$

Copyright (c) 2010 CLINICS - This is an Open Access article distributed under the terms of the Creative Commons Attribution Non-Commercial License (http:// creativecommons.org/licenses/by-nc/3.0/) which permits unrestricted noncommercial use, distribution, and reproduction in any medium, provided the original work is properly cited. researchers proposed that an impaired leptin secretion or signalling might play a role in antipsychotic-induced weight gain.

Adiposity and weight gain are closely associated with severe health problems, including hypertension, type II diabetes, and coronary disease. Moreover, weight gain under antipsychotic treatment may reduce compliance and cause patients to abandon the medication. This endangers treatment success and causes a risk of critical deterioration of the psychiatric condition. Therefore, the availability of antipsychotic drugs without the side effect of weight increase appears to be fundamental for effective and cost-efficient treatment of schizophrenia. The mechanisms underlying antipsychotic-induced weight gain, however, are poorly understood. Plausible explanations include reduced physical activity, metabolic changes resulting in reduced calorie burnoff, stronger appetite resulting in increased food intake, ${ }^{5,6}$ and differences in receptor binding profiles. ${ }^{7}$

In the complex physiological network regulating food intake, energy expenditure, and fat storage, researchers 
have found that leptin plays a key role. Leptin, a polypeptide product of the obese (OB) gene, is secreted by adipocytes. Its expression and secretion shows a strong positive correlation with body fat mass and adipocyte number and size. ${ }^{8}$ Leptin, together with other hormones, including glucocorticoids, amylin, and insulin, plays an important role in regulating food intake, energy expenditure, body weight homeostasis, ${ }^{9}$ reproduction function, and neuroendocrine responses. ${ }^{10}$ The lack of leptin results in hormonal and metabolic alterations and a dramatic increase in body weight. ${ }^{11}$ One of the primary tasks of leptin is sending information to the central nervous system - especially hypothalamic areas - about the amount of energy stored in the adipose tissue. In the brain, leptin interacts with the Ob-R receptor found in both rodents and humans. The leptin receptor is a class I cytokine receptor, a single-membranespanning protein that has several isoforms due to alternative splicing. ${ }^{12}$ The short form $\mathrm{Ob}-\mathrm{Ra}$ and the long form $\mathrm{Ob}-\mathrm{Rb}$ are both abundantly expressed in the hypothalamus.

Haloperidol, which produces little or no weight gain, acts primarily on the dopamine D2 receptors, whereas clozapine has a high affinity with the histamine $\mathrm{H} 1$ and the serotonin 5-HT2C receptors. Both $\mathrm{H} 1$ and 5-HT2C receptors are implicated in the control of food intake and body weight. ${ }^{13}$ Furthermore, the histamine $\mathrm{H} 3$ receptor seems to play a key role in the regulation of food intake and hunger by inhibiting other neurotransmitters, such as serotonin, noradrenaline, and acetylcholine, and by controlling the synthesis and release of histamine. ${ }^{14}$ Studies have shown increased leptin concentrations in psychiatric patients treated with clozapine or conventional antipsychotics ${ }^{15}$ and also in noncompliant patients, but not in antipsychotic-naïve, first-episode schizophrenic patients. ${ }^{16}$ Haupt et al. ${ }^{17}$ detected no differences in the plasma leptin concentrations of patients medicated with antipsychotic drugs and healthy controls. However, Thakore et al. ${ }^{18}$ showed that drug-naive and drug-free patients with schizophrenia exhibit increased intra-abdominal fat and that people with schizophrenia appear to be overweight more often than those in the general population. ${ }^{19}$

Experimental studies on rodents can help researchers to understand the mechanisms underlying antipsychoticinduced metabolic changes. Numerous studies of both classical and atypical antipsychotic drugs have demonstrated changes in body weight, food consumption, or body fat composition associated with the release of leptin. Increasing serum leptin levels in male Sprague Dawley rats after long-term treatment using haloperidol and olanzapine added to food were substantiated in a study by MinetRinguet et al. ${ }^{20}$ Chronic clozapine application in female Wistar rats showed a negative correlation between serum leptin levels and the given doses (i.p.). ${ }^{21}$ In our study, we aimed to clarify the effect of typical and atypical antipsychotic drugs on blood leptin secretion and hypothalamic leptin receptor expression. These results were correlated with weight gain and food and water consumption after a 6week period of selective treatment with haloperidol, clozapine, or ziprasidone mixed with food.

\section{METHODS}

\section{Animals and housing conditions}

All experiments were carried out in accordance with the local laws governing animal experimentation and approved by Bezirksregierung Düsseldorf authorities. On postnatal day 21 (PD 21), male pups of Wistar rats (outbreed strain, animal facility Düsseldorf, Heinrich-Heine-University of Düsseldorf) were removed from their mothers and were individually housed on PD 85 with free access to water and dry, ground food pellets containing $15 \%$ fat. They were maintained on a 12:12 light/dark cycle (lights off at $20.00 \mathrm{~h}$ ) at a temperature of $21^{\circ} \mathrm{C}$ and $60 \%$ humidity. To limit the possible impact of individual weight gain of the test animals, the rats derived from litters with identical pup numbers, so each group was equally composed of rats with different parentage.

\section{Preliminary dose test}

Based on the results of Kapur et al., ${ }^{22}$ which showed that the current dosing of haloperidol in animal studies is inappropriately low in chronic dosing studies, we tested 3 different daily doses of each antipsychotic drug added to ground food pellets: 2, 5, and $8 \mathrm{mg}$ haloperidol (Haloneural, Hexal, Germany)/ kg body weight (BW); 20, 40, and $50 \mathrm{mg}$ clozapine (Leponex, Novartis, Germany)/ kg BW; and 10, 20, and $25 \mathrm{mg}$ ziprasidone (Zeldox, Pfizer, Germany)/ kg BW. Each dose was tested in 3 animals beginning at the age of 12 weeks. Weight gain and food consumption in $\mathrm{g}$ per $100 \mathrm{~g} \mathrm{BW}$ were measured during a 2-week period, and the serum level of haloperidol, clozapine, and N-desmethylclozapine were determined by HPLC in $\mathrm{ng} / \mathrm{ml}$.

\section{Assessment of food and water consumption}

Starting at week 11 (PD 71), the animals were weighed twice per week ( $a=$ first weighing on Tuesday and $\mathrm{b}=$ second weighing on Friday), and their weekly water consumption was calculated. Each animal's food consumption was measured each day and averaged for a week, including the loss of ground pellets in the litter. Based on the preliminary dose studies starting at week 13 (PD 85), each of the 20 animals in a trial group received an average daily dose of $3.5 \pm 0.03 \mathrm{mg} / \mathrm{kg}$ BW haloperidol, $30.6 \pm$ $0.22 \mathrm{mg} / \mathrm{kg}$ BW clozapine, or $14.9 \pm 0.13 \mathrm{mg} / \mathrm{kg}$ ziprasidone in a measured quantity of ground pellets. Serum levels of haloperidol and clozapine by HPLC showed that this route of administration leads to pharmacologically active plasma levels. The control group (20 animals) was fed only ground pellets.

\section{Assessment of serum leptin levels}

On PD 96 (week 14) and PD 110 (week 16), blood samples were taken from the retro-orbital plexus of anesthetised animals with $150 \mathrm{~mm}$ glass Pasteur pipettes (Brand, Germany).

The blood samples were centrifuged, and the leptin blood serum level was determined by using a rat leptin assay kit (IBL, Japan) in ng/ml. On PD 127 (week 19), the animals were sacrificed by $\mathrm{CO}_{2}$ inhalation, and their blood was sampled by cardiac puncture. The brains were removed and immediately frozen in 2-methylbutane (Merck, Germany), cooled down by liquid nitrogen, and stored at $-80^{\circ} \mathrm{C}$. The serum levels of leptin in the heart blood were determined using a rat leptin assay kit (IBL, Japan) in $\mathrm{ng} / \mathrm{ml}$. Additionally, the serum levels of haloperidol and clozapine (clozapine and N-desmethylclozapine) in the heart blood were analyzed using HPLC in $\mathrm{ng} / \mathrm{ml}$. Ziprasidone was not measurable since an HPLC method has not been established. 


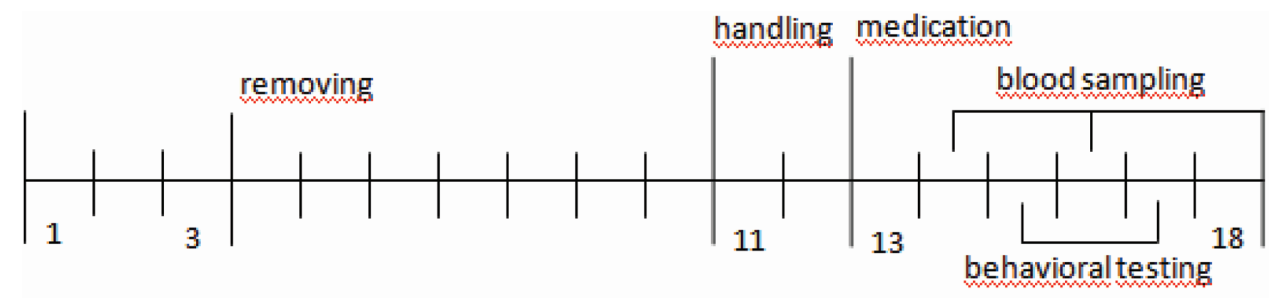

age (weeks)

Figure 1 - Timeframe of experimental setup. The male Wistar pups were removed from their mothers at PD 21, housed together, and received ground pellets at this time. At week 11 and 12, the rats were weighed twice per week and were habituated to the activity and alcove box. At week 13, the animals were medicated with haloperidol, clozapine, or ziprasidone ( $n=20$ for all groups) or were fed only ground pellets (controls, $n=19$ ). At week 12 and 14, blood was sampled. At weeks 15 and 17 , activity and anxiety behavior was tested. After 6 weeks of medication, the rats were anesthetized and their blood and brains were removed.

\section{Horizontal locomotor activity and alcove test}

Around week 11 and 12, the animals were habituated to the experimental setup. Locomotor activity under antipsychotic drug medication was measured compared to that of non-treated controls using an open field activity test in a standard box $(40 \times 40 \times 30 \mathrm{~cm})$. Animal movement was restricted to the square acrylic inner cage that was closed with a perforated lid. On PD 102 (week 15) and PD 116 (week 17), respectively, the animals were individually placed into the center of the field and observed for $20 \mathrm{~min}$ in the dark. Locomotion was assessed automatically using photocells. In the alcove test, which is a refined open field exploratory test, ${ }^{23}$ the rats were individually placed into a small dark start box connected to a brightly-lit open field by a guillotine door. The door of the box was opened and the latency to leave the box was measured. Each trial ended after $2 \mathrm{~min}$ and was repeated after $30 \mathrm{~min}$. The scores of the two tests were totalled.

\section{Semiquantitative detection of the leptin receptor}

Hypothalami of the brains, which were frozen and stored at $-80^{\circ} \mathrm{C}$, were dissected, weighed, and homogenized in $0.25 \mu$ ice-cold lysis buffer ${ }^{24}$ (50 mM Hepes pH 7,9; 10\% glycerol; $1 \mathrm{mM}$ EDTA; $1 \mathrm{MM}$ sodium pyrophosphate; $1 \mathrm{mM}$ sodium fluoride; $1 \mathrm{mM}$ sodium vanadate; $1 \mathrm{mM}$ PMSF; containing a proteinase inhibitor, diluted 1:50, Sigma P 8340). Nonidet P-40 and Triton X-100 were added to a final concentration of $1 \%$. After $30 \mathrm{~min}$ on ice, the homogenates were centrifuged at $4^{\circ} \mathrm{C}$ at $13000 \mathrm{U}$ for $10 \mathrm{~min}$. Proteins in the supernatant were precipitated with A/G Plus-Agarose (Santa Cruz Biotechnology, sc-2003) following the manufacturer's specifications. The precipitates were centrifuged after $10 \mathrm{~min}$ on ice at $13000 \ddot{U}$ for $10 \mathrm{~min}$ at $4{ }^{\circ} \mathrm{C}$. The supernatant was discarded and the sediment resolved in an SDS buffer (0.005 DTT and 0.01 DTE resolved in $50 \mu \mathrm{l}$ distilled water and $450 \mu \mathrm{l} 25 \%$ SDS diluted 1:6 in 0.05 M Tris$\mathrm{HCl} \mathrm{pH} \mathrm{8.8).} \mathrm{The} \mathrm{proteins} \mathrm{were} \mathrm{stored} \mathrm{at}-80^{\circ} \mathrm{C}$. The protein content of each sample was determined. For a Western blot analysis, $30 \mu \mathrm{g}$ protein were resolved by SDS-PAGE $(7.5 \%$ polyacrylamide in the separating gel) and transferred to a PVDF membrane (Invitrolon PVDF $0.45 \mu \mathrm{m}$ pore size, Invitrogen, Carlsbad USA). Membranes were incubated in TBS-T with $7.5 \%$ nonfat milk overnight at $4{ }^{\circ} \mathrm{C}$ followed by $2 \mathrm{~h}$ at room temperature with mouse monoclonal OB-R antibody (diluted 1:400, Ob-R B-3; Santa Cruz Biotechno$\log y)$, which detects the short and long isoforms of the receptor, and goat polyclonal actin antibody (1:800, Akt 1 C-
20; Santa Cruz Biotechnology). To identify immunoreactive bands, membranes were subsequently incubated with HRPconjugated secondary antibodies (goat anti-mouse HRP IgG and donkey anti-goat HRP IgG, respectively; diluted 1:5000 for detection of Ob-R and 1:10000 for detection of actin 1, Santa Cruz Biotechnology). Signals were visualized using a chemiluminescence detection kit (Santa Cruz Biotechnology) on Kodak BioMax Light film (Kodak Industries, Chalon-sur-Saone, France). Resultant autoradiographs were quantified by densitometry using Gene Snap and Gene tools software (Syngene, Synoptics Ltd, United Kingdom).

\section{Statistical analysis}

All data are presented as mean \pm SEM. The data were analysed by two-way analyses of variance (ANOVA) with GROUP as the between-group factor and WEEKS as the repeated measures factor unless otherwise specified. Posthoc tests with $\alpha$-adjustment for repeated measurement were carried out for single measurement points.

A bivariate correlation procedure using the SpearmanRho coefficient was carried out to test the relationship between food consumption and the level of leptin in the serum. We also tested the correlation between the level of leptin in the heart blood and the animal's weight before death and the correlation between the level of leptin and the amount of haloperidol and clozapine (clozapine and its main metabolite $\mathrm{N}$-desmethylclozapine) in the serum.

\section{RESULTS}

\section{Preliminary dose test}

We found an inverse dose / body weight gain correlation of haloperidol and ziprasidone over 2 weeks with equal results for food consumption. Animals fed with clozapine showed the highest percentage of weight gain at $40 \mathrm{mg} / \mathrm{kg}$ BW with equal results for food consumption. But a one-way ANOVA revealed no differences among the groups for body weight gain and food consumption (all $\mathrm{p} \geq 0.05$ ).

At daily $2 \mathrm{mg} / \mathrm{kg} \mathrm{BW}$, haloperidol was not detectable in the serum using HPLC. At $8 \mathrm{mg} / \mathrm{kg}$ BW, the side effects of haloperidol, e.g., apathy, were very pronounced. Therefore, we chose a daily dose of $5 \mathrm{mg} / \mathrm{kg}$ BW haloperidol. At $20 \mathrm{mg} / \mathrm{kg} \mathrm{BW}$, we detected only a low serum level of clozapine, and its metabolite was not discernible. After discovering a lower weight gain and food intake at $20 \mathrm{mg}$ and $50 \mathrm{mg}$ clozapine, we decided to apply a daily dose of $40 \mathrm{mg} / \mathrm{kg}$ BW. We chose a daily dose of $20 \mathrm{mg} / \mathrm{kg}$ BW of 
Table 1 - Preliminary dose-finding test.

\begin{tabular}{|c|c|c|c|c|}
\hline mg/kg BW/day & $\%$ BW & food intake/100g BW (g) & drug serum level $(\mathrm{ng} / \mathrm{ml})$ & $\mathrm{N}$-desmethyl serum level $(\mathrm{ng} / \mathrm{ml})$ \\
\hline 2 haloperidol & $20.8 \pm 1.8$ & $5.5 \pm 0.3$ & 0 & \\
\hline 5 & $18.9 \pm 2.5$ & $5.3 \pm 0.4$ & $65.8 \pm 15.1$ & \\
\hline 8 & $17.5 \pm 0.8 \vee$ & $5.1 \pm 0.1 \vee$ & $94.26 \pm 12.1 \vee$ & \\
\hline 20 clozapine & $27.5 \pm 0.6$ & $5.7 \pm 0.1$ & $55.5 \pm 9.6$ & 0 \\
\hline 40 & $28.8 \pm 1.8$ & $6.3 \pm 0.4$ & $75.5 \pm 3.1$ & $36.7 \pm 7.7$ \\
\hline 50 & $26.1 \pm 0.8$ & $6.0 \pm 0.2$ & $110.6 \pm 28.1 \vee$ & $182.0 \pm 26.1 \vee$ \\
\hline 10 ziprasidone & $20.2 \pm 0.9$ & $5.4 \pm 0.2$ & & \\
\hline 20 & $18.0 \pm 1.8$ & $5.3 \pm 0.3$ & & \\
\hline 25 & $16.0 \pm 1.2 \vee$ & $5.0 \pm 0.1 \vee$ & & \\
\hline
\end{tabular}

ziprasidone (corresponding to a real weekly dose of $14.6 \mathrm{mg} / \mathrm{kg} \mathrm{BW}$ ), according to Pillai et al. ${ }^{25}$.

One finding of the preliminary dose test was the fact that rats did not eat all of the allocated food each day. Therefore, in the main trial, we calculated the real weekly dose and averaged it over the test period. We calculated a mean dose of $3.5 \pm 0.03 \mathrm{mg}$ haloperidol/ $\mathrm{kg} \mathrm{BW}, 30.6 \pm 0.22 \mathrm{mg}$ clozapine/ $\mathrm{kg}$ BW and $14.9 \pm 0.13 \mathrm{mg}$ ziprasidone/ $\mathrm{kg}$ BW.

\section{Weight gain}

Before starting the medication at the age of 11 and 12 weeks (data are not shown in Figure 1 because we refer to the percentage body weight gain on the first weighing after beginning the drug application), the animals' weight showed a significant difference over time, with weights increasing for animals in all groups $[\mathrm{F}(3,165)=699.3, \mathrm{p}<$ $0.00000]$, but there were no differences among the groups $[\mathrm{F}(3,55)=0.41, \mathrm{p}=0.75]$ and in the WEEKS*GROUP $[\mathrm{F}(9,165)=0.6, \mathrm{p}=0.8]$. This indicates that the alterations in body weight among the groups after week 12 resulted from the antipsychotic medication.

We found a continuous weight gain in all four groups over 6 weeks of drug application. The percentage increase in weight referred to the first weighing after the onset of antipsychotic medication and showed significant differences (Fig.1) for WEEKS $[\mathrm{F}(11,803)=537.54, \mathrm{p}<0.00000]$, WEEKS*GROUP $[\mathrm{F}(33,803)=11.11, \mathrm{p}<0.00000]$, and GROUP $[F(3,73)=14.6, p<0.00000]$, with the highest increase in the control group, followed by the clozapine and the ziprasidone groups, and the lowest gain for the haloperidol group.

Post-hoc tests revealed that the values of the haloperidol group were significantly lower compared to controls (week $13 \mathrm{~b} p=0.001$, week $15 \mathrm{a} \mathrm{p}=0.004$, week $15 \mathrm{~b} \mathrm{p}=0.0002$, week $16 \mathrm{a} p=0.0002$, week $16 \mathrm{~b} \mathrm{p}=0.0003$, week $17 \mathrm{a} \mathrm{p}=0.0002$, week $17 \mathrm{~b} p=0.0001$, week $18 \mathrm{a} p=0.0002$, and week $18 \mathrm{~b}$ $\mathrm{p}=0.00003$, respectively) and the clozapine group over all weeks except for week 14 (week $13 b \mathrm{p}=0.001$, week $15 b$ $p=0.001$, week 16a $p=0.001$, week $16 \mathrm{~b} p=0.001$, week $17 \mathrm{a}$ $\mathrm{p}=0.002$, week $17 \mathrm{~b} \mathrm{p}=0.001$, week $18 \mathrm{a} \mathrm{p}=0.001$, and week $18 \mathrm{~b} p=0.00008$, respectively). Animals with ziprasidone medication showed decreased body weight compared to the control group from week 16 to week 18 (week $16 \mathrm{a} p=0.003$, week 17a $p=0.001$, week $17 b \quad p=0.002$, and week 18a $p=0.004)$, but there were no differences between the ziprasidone and the clozapine groups and between animals

\section{$\%$ weight gain}

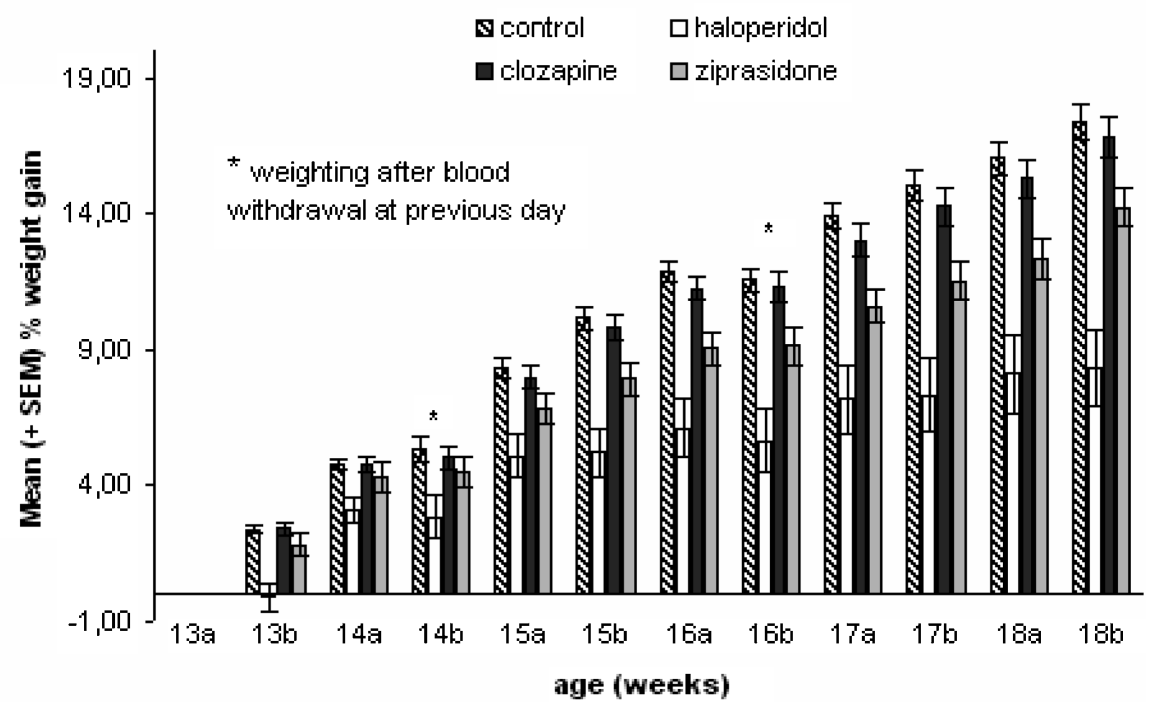

Figure 2 - Percentage weight gain of male Wistar rats: control $(n=19)$ and animals treated with haloperidol, clozapine, and ziprasidone ( $n=20$ for all groups). All animals were weighed twice per week. Depicted is the weight after application of the antipsychotic drugs from week 13 to week 18. No difference was found between the control and clozapine groups. The haloperidoltreated animals gained less weight than the control and clozapine group directly after medication, whereas the ziprasidone group gained less weight after 4 weeks of treatment than the control group with $p \leq 0.004$ considered significant. 
fed with ziprasidone and haloperidol. In the tested period, no differences were detectable between the control and the clozapine group (all $\mathrm{p}>0.004$ ).

\section{Food consumption}

We averaged the food consumption of each day over a week, based on $100 \mathrm{~g} \mathrm{BW}$ (Fig.2), avoiding the influence of the individual animals' body weight on the results. Taking into consideration the loss of ground pellets in the litter, we subtracted the pellet parts, screened from the litter, from the total weekly food quantity.

Statistical analysis revealed a significant decrease in food consumption per $100 \mathrm{~g} \mathrm{BW}$ over time $[\mathrm{F}(1,55)=40.48$, $\mathrm{p}<$ 0.00000], but there were no differences for the WEEKS*GROUP $[\mathrm{F}(3,55)=2.01, \mathrm{p}=0.12]$ and GROUP $[F(3,55)=0.66, p=0.58]$ over the 2 weeks of testing before antipsychotic application. Therefore, we concluded that the differences among the four groups were a consequence of drug medication.

After application of antipsychotic drugs, food consumption continuously decreased over time $[\mathrm{F}(5,365)=179.41$, $\mathrm{p}<0.00000]$. For WEEKS*GROUP $[\mathrm{F}(15,365)=2.96$, $\mathrm{p}=0.0002]$ and among the groups $[\mathrm{F}(3,73)=9.72, \mathrm{p}=$ $0.00002]$, we also found significant differences. The highest food consumption level occurred in the control group, and the lowest was in the haloperidol group. Posthoc tests showed that at week 13 the groups did not differ with reference to food consumption (all $\mathrm{p}>0.008$ ). From week 14 to 18 , the food intake decreased significantly for the haloperidol group compared with the control group $(\mathrm{p}=$ $0.004, \mathrm{p}<0.00000, \mathrm{p}=0.0003, \mathrm{p}=0.0002$ and $\mathrm{p}=0.00001$, respectively). At week 15 and 18, we also discovered differences between the control and ziprasidone-treated animals ( $\mathrm{p}=0.001$ and $\mathrm{p}=0.008$, respectively). At weeks 15,17 , and 18 , the level of food consumption of the rats with

\section{Weekly food consumption}

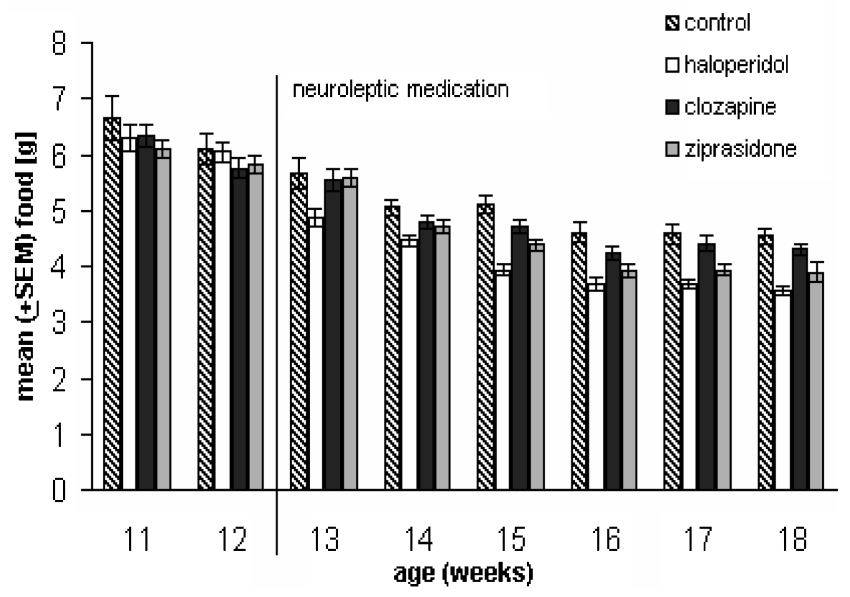

Figure 3 - Weekly food consumption based on $100 \mathrm{~g}$ BW of male Wistar rats: control $(n=19)$ and animals treated with haloperidol, clozapine, or ziprasidone ( $n=20$ for all groups). All animals showed decreased food consumption from week 11 to week 18 with no differences before medication. Animals under haloperidol medication ate less than the control and clozapine groups after 1 week of application. Ziprasidonetreated rats ate less than the controls after 3 week of medication. We found no differences between the control and clozapine groups with $p \leq 0.008$ considered significant. haloperidol medication differed from those treated with clozapine $(\mathrm{p}=0.0004, \mathrm{p}=0.004$ and $\mathrm{p}=0.001$, respectively). We detected no such differences between the clozapine and ziprasidone groups, between the control and clozapine groups, and between the haloperidol and ziprasidone groups (all p $>0.008$, accounting for the $\alpha$ adjustment).

\section{Weekly water consumption}

Water consumption was measured weekly. To avoid a bias due to individual development of body weight over time, water consumption was related to $100 \mathrm{~g}$ BW (Fig. 3).

The one-way ANOVA showed no differences among the groups at week $12(\mathrm{p}=0.27)$. Thus, we concluded that further differences in the course of the experiment between the four groups were a consequence of antipsychotic medication.

After the administration of the drugs, an ANOVA for repeated measures showed no differences between WEEKS*GROUP $[F(15,170)=1.26, p=0.23]$. Significant differences were found from week 13 to week 18 (WEEKS $[\mathrm{F}(5,170)=22.74, \mathrm{p}<0.00000])$ and among the drug groups (GROUP $[\mathrm{F}(3,34)=47.1, \mathrm{p}<0.00000]$. Controls and clozapine-medicated rats did not differ in drinking behavior from week 13 to week 18 (all $\mathrm{p}>0.008$ ). In addition, the behavior of the haloperidol-medicated animals was no different than the behavior of rats medicated with ziprasidone (all p > 0.008). Significant differences were found between controls and clozapine-medicated animals on the one side and haloperidol- and ziprasidone-treated rats on the other side during the course of the complete testing period ( $\mathrm{p} \leq 0.008$ at all measuring points). Any correlation between the real body weight and the water consumption was not verifiable.

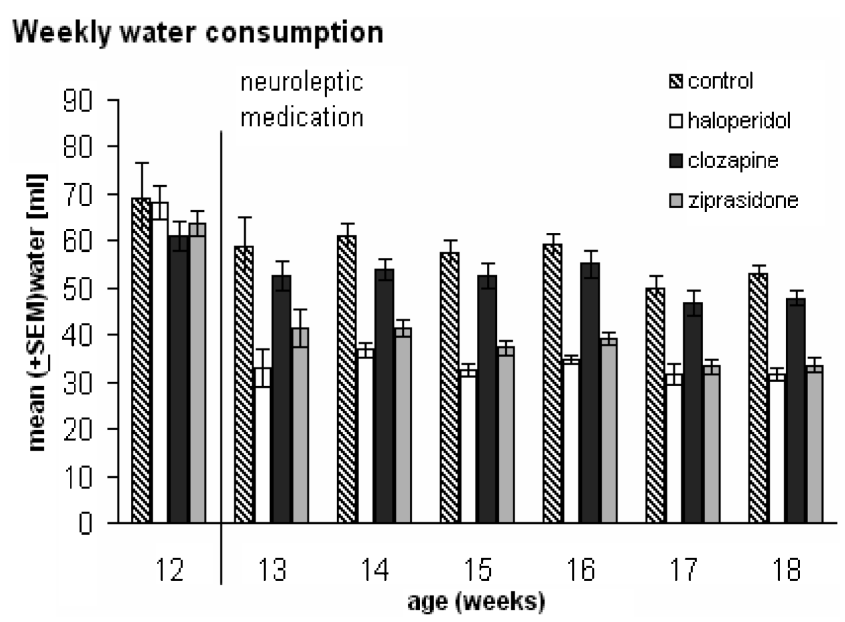

Figure 4 - Weekly water consumption based on $100 \mathrm{~g} \mathrm{BW}$ of male Wistar rats: control $(n=19)$ and animals treated with haloperidol, clozapine, or ziprasidone ( $n=20$ for all groups). All animals showed slightly decreased water consumption from week 11 to week 18 but no differences before medication. Animals under haloperidol and ziprasidone medication drank less than the control and clozapine groups after 1 week of application. We found no differences between the control and clozapine groups with $p \leq 0.008$ considered significant. 


\section{Horizontal locomotor activity and alcove test}

To examine the sedating impact of the neuroleptics, we investigated locomotor activity and exploratory behavior in the alcove test at weeks 15 and 17.

We found a decrease in the activity counts (Fig. 4A) from week 15 to $17[\mathrm{~F}(1,73)=40.59, \mathrm{p}<0.00000]$ with high levels in the control group and the group treated with clozapine, followed by the group treated with ziprasidone, and an unexpected low activity in the haloperidol group. The activity counts for weeks 15 and 17 were significantly different among the control, clozapine, and ziprasidone groups $(\mathrm{p}=0.005, \mathrm{p}=0.001$ and $\mathrm{p}=0.001$, respectively), but not in the haloperidol group $(\mathrm{p}=0.18)$. We also found differences for the WEEKS*GROUP $[\mathrm{F}(3,73)=3.01, \mathrm{p}=$ 0.035] and GROUP $[\mathrm{F}(3.73)=12.54, \mathrm{p}<0.00000]$. The animals treated with haloperidol in week 15 ( $p=0.00002$ vs. control group, $\mathrm{p}=0.00007$ vs. clozapine group and $\mathrm{p}=$ 0.001 vs. ziprasidone group) and week 17 ( $p=0.001$ vs. control group, $\mathrm{p}=0.004$ vs. clozapine group and $\mathrm{p}=$ 0.02 vs. ziprasidone group) differed from the other groups, whereas the controls and the animals treated with clozapine and ziprasidone did not show differences.

In the alcove test, we found an increase in the latencies (Fig. 4B) spent in the dark box from week 15 to 17 as expected $([\mathrm{F}(1,73)=45.73, \mathrm{p}<0.00000])$. Posthoc tests revealed that the increase was not significant for all groups ( $p=0.007$ for the control groups; $p=0.003$ for the haloperidol group, $\mathrm{p}=0.005$ for the clozapine group, and $\mathrm{p}$ $=0.001$ for the ziprasidone group). No differences were found for the WEEKS*GROUP $[\mathrm{F}(3,73)=0.21, \mathrm{p}=0.89]$ and GROUPS $[\mathrm{F}(3,73)=3.73, \mathrm{p}=0.05]$.

\section{Blood leptin and drug concentration and leptin receptor expression in the hypothalamus}

We found a mean value of $18.3 \pm 2.7 \mathrm{ng} / \mathrm{ml}$ haloperidol, $14.4 \pm 2.2 \mathrm{ng} / \mathrm{ml}$ clozapine, and $134.0 \pm 26.9 \mathrm{ng} / \mathrm{ml} \mathrm{N}$ desmethylclozapine in the serum after 6 weeks of antipsychotic drug application.

Serum levels of leptin increased over time in the control, clozapine, and ziprasidone groups, whereas the haloperidol-medicated group showed a maximum after 4 weeks of drug application. Although the overall leptin concentration in blood did not change over time (WEEKS $[\mathrm{F}(2,134)=2.76$, $\mathrm{p}=0.067])$, differences were found for the WEEKS*GROUP $[\mathrm{F}(6,134)=2.18, \mathrm{p}=0.049]$ and $\operatorname{GROUPS}[\mathrm{F}(3,67)=5.31$, $\mathrm{p}=0.002]$. Posthoc tests showed significant differences between the clozapine and ziprasidone groups two weeks after medication $(\mathrm{p}=0.005)$. All other groups yielded no significant differences $(\mathrm{p}>0.016)$.

To investigate the drug's impact on leptin receptor expression in the hypothalamus, we performed Western blot and immunohistochemical experiments. No differences in receptor expressions were discovered among the four groups.

\section{Correlation between food consumption, drug quantity, weight before death and blood leptin concentrations}

We could not substantiate a significant correlation between food consumption and leptin blood concentrations. No correlation was detected between antipsychotic drug levels and leptin concentration.

The bivariate correlation procedure showed a significant positive effect (Sperman's Rho correlation coefficient 0.567, $p=0.01$ ) between the weight of the animals (weight before death) treated with haloperidol and leptin concentration. No correlation was found in the other groups.

\section{DISCUSSION}

In this study, medication of male Wistar rats with haloperidol, clozapine, and ziprasidone caused heterogenous effects on weight gain, food and water intake, and sedation compared to controls. The blood leptin concentration, however, was not different among the four groups, and there were no age-dependent effects within the groups. Moreover, there were no significant differences in the leptin receptor expression in the hypothalami of medicated or untreated animals.

Medication of rats with clozapine did not induce the typical side effects known from observations in humans, including weight gain, ${ }^{19}$ decreased physical activity, ${ }^{26}$ and abnormal eating behavior like food craving or binge eating. ${ }^{6}$ However, we cannot exclude the fact that clozapine induced body fat deposition in rats without increasing their body
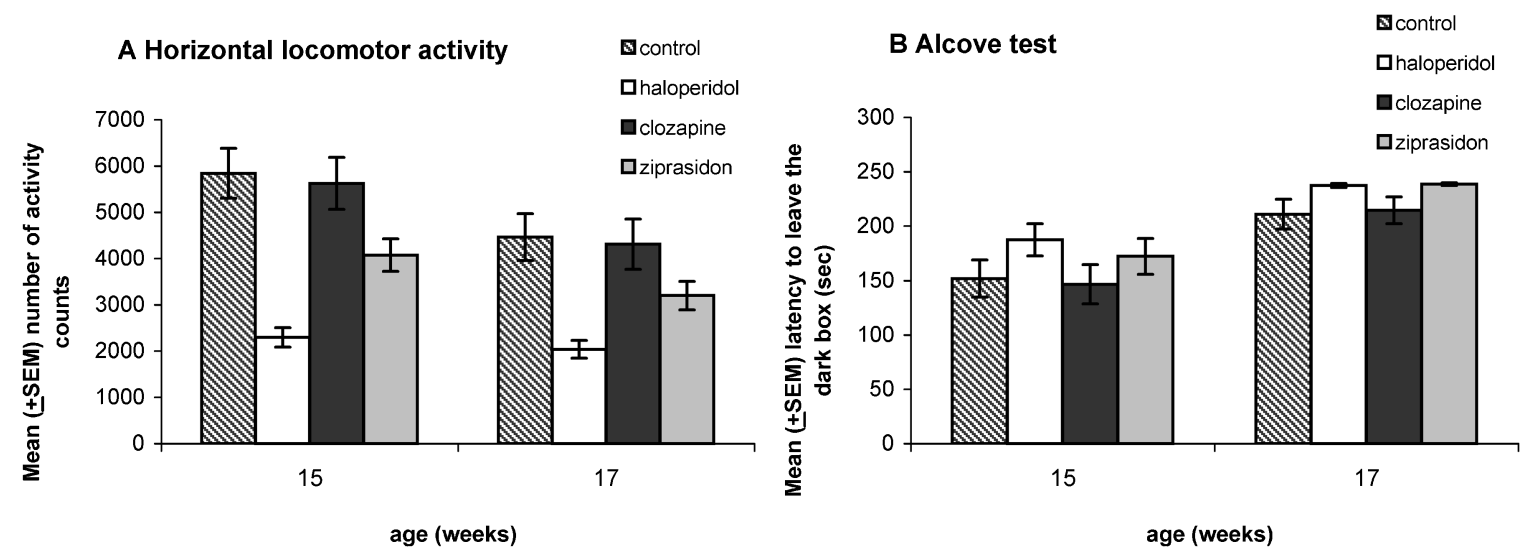

Figure 5 - Horizontal locomotor activity behavior in the alcove test of male Wistar rats: control $(n=19)$ and animals treated with haloperidol, clozapine, or ziprasidone ( $n=20$ for all groups). Haloperidol-medicated animals showed significantly reduced activity with no habituation effect in contrast to the control, clozapine, and ziprasidone groups with $\mathrm{p} \leq 0.025$. Rats medicated with haloperidol and ziprasidon showed a higher latency in the alcove test and the results were not significantly higher than in the control and clozapine groups. 


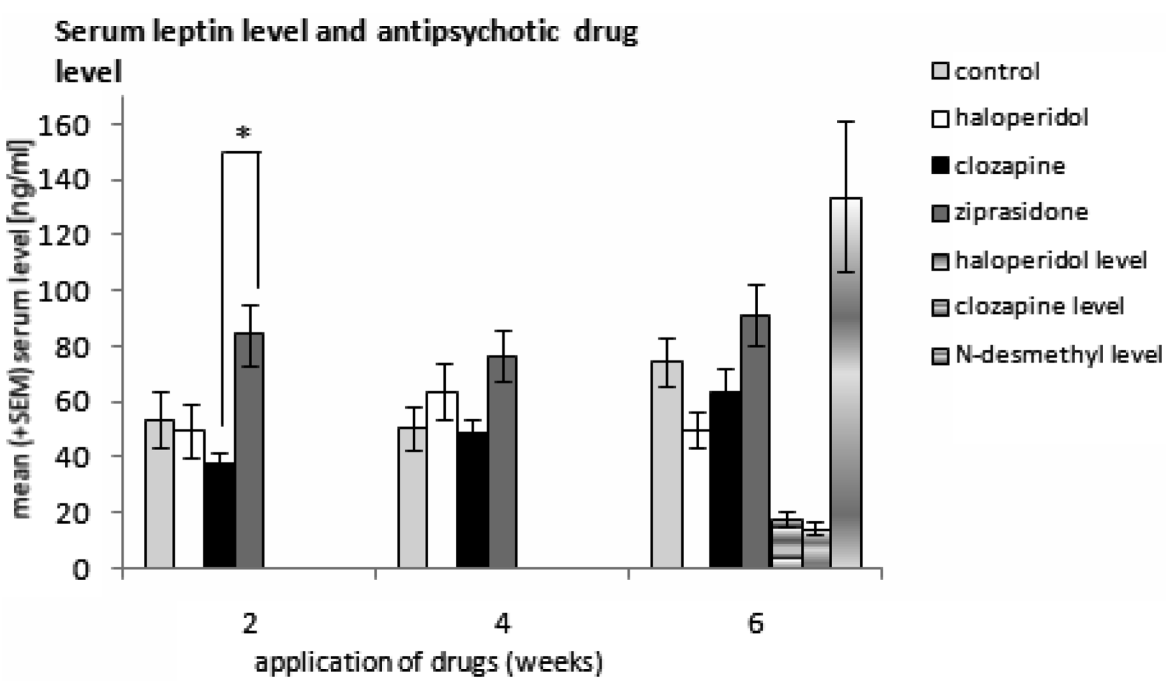

Figure 6 - Serum leptin level of male Wistar rats after 2, 4, and 6 weeks of antipsychotic drug application and serum level of haloperidol and clozapine: control $(n=19)$ and animals treated with haloperidol, clozapine, or ziprasidone $(n=20$ for all groups). Serum levels of leptin increased over time in the control, clozapine, and ziprasidone groups, whereas the haloperidol-medicated group showed a maximum increase after 4 weeks of drug application. But significant differences of serum leptin levels were found after only 2 weeks of medication between the clozapine and ziprasidone groups with $\mathrm{p} \leq 0.016$. After 6 weeks, the level of $\mathrm{N}$-desmethyl clozapine in the serum is 10 times higher than the level of clozapine.

weight or metabolic abnormalities as described. ${ }^{20,21,27}$ To clarify this point, in future studies of weight gain after antipsychotic drug medication in rats, visceral white fat depositions have to be determined.

In most rodent studies, antipsychotics were administered by using daily gavage, drinking water, ${ }^{28}$ food, and intraperitoneal or subcutaneous injections. Drug administration by food is the least-invasive application manner, reduces handling stress, and allows the exact determination of food and drug intake. ${ }^{29}$ The plasma half-life of neuroleptic drugs lasts much longer in humans than in rodents. According to Minet-Ringuet et al. ${ }^{20}$ it is plausible that by mixing antipsychotics into the food, more consistent drug blood levels are maintained, so this is a more promising approach to model drug application in the human.

\section{Weight gain, food and water consumption}

The observed effects on weight gain and food and water consumption are likely to be due to the medication itself because no differences were detectable among the groups before the application of the antipsychotic drugs. Compared to control animals, rats medicated with clozapine showed a small decrease in weight gain as well as food and water consumption although these differences were not significant. Rats with haloperidol medication gained less body weight than all other groups immediately after application. We measured significant differences in weight gain among animals in the haloperidol group compared to controls and animals medicated with clozapine but not in those medicated with ziprasidone. After one week of drug treatment, rats with haloperidol medication ate and drank significantly less than controls and the clozapine group. Hartfield et al. ${ }^{30}$ showed that low doses of haloperidol decreased drinking of a fat emulsion while clozapine was associated with an increased intake. Yoshida et al. ${ }^{31}$ observed a suppression of body weight gain in male rats under a low oral haloperidol application that was not accompanied by changes in food consumption but by reduced water intake. In contrast, Minet-Ringuet et $\mathrm{al}^{32}$ found no differences in body weight, body composition, and food consumption among animals treated with a lower dose of haloperidol and controls. Lee et al. ${ }^{33}$ also observed small changes in food or water consumption at low doses of haloperidol and clozapine. Thus, we conclude that our observed sharp effects of haloperidol on weight gain and food and water consumption are due to the high drug dose applied $(3.5 \pm 0.03 \mathrm{mg} / \mathrm{kg} \mathrm{BW})$. We have not observed vacuous chewing movements following the dose of haloperidol used in the present study, so it is unlikely that the decreased food and water consumption among rats under the haloperidol application was due to a malfunction of the mandible. However, Sanci et al. ${ }^{34}$ found significantly increased vacuous chewing movements in haloperidolmedicated rats $(1.5 \mathrm{mg} / \mathrm{kg}$ i.p.), suggesting D1 receptor stimulation and possibly receptor supersensitivity.

After three weeks of ziprasidone medication, rats showed a significant decrease in weight gain compared to controls, but there was no statistical difference compared to the clozapine or haloperidol groups over the whole experiment period. Food consumption was significantly reduced in comparison to the controls after two weeks of drug treatment, and water consumption decreased after one week in comparison to the control and clozapine groups. Therefore, in contrast to the animals treated with haloperidol, the effects on weight gain among those in other groups were possibly caused by decreased food consumption.

As described by Davoodi et al. ${ }^{35}$ and Fell et al., ${ }^{36}$ ziprasidone intake is not associated with weight gain and hyperphagia in either humans or rodents. Although ziprasidone is an atypical antipsychotic drug, its effects on weight gain and food and water consumption show a delay in time comparable to that seen with the use of the typical antipsychotic haloperidol. Terry et al. ${ }^{37}$ reported that in rats, ziprasidone has less pronounced behavioral effects, and neurochemical deficits appear to be more delayed. 
Mechanisms underlying drinking behavior remain unclear. There is some evidence that nitric oxide plays a role in the regulation of drinking. ${ }^{38}$ Studies have shown that the brain's L-arginine/NO pathway may be involved in the central effect of leptin on feeding behavior and body weight gain in mice ${ }^{38}$ and chickens. ${ }^{40}$ These mechanisms must be substantiated by further investigations.

We found a positive correlation for all 4 groups between food intake and body weight before blood sampling. Only the animals medicated with haloperidol showed a positive correlation between body weight and serum leptin levels after 6 weeks of drug application. While our data do not exclude the possibility that a chronic application of haloperidol might have a decreasing impact on number, size, or leptin secretion rate of adipocytes proportional to the body weight, it must be noted that Minet-Ringuet et al. ${ }^{41}$ did not observe any effects of haloperidol on cell size, lipolytic activity, and glucose transport activity in rat adipocytes after oral treatment for five weeks.

\section{Horizontal locomotor activity and alcove test}

In the alcove test, which assesses fear and anxiety, we found no differences among animals in the four groups. Rats with haloperidol medication showed a highly significant decrease in locomotor activity compared to those in the other groups. Interestingly, there was a habituation effect over time in controls and in rats medicated with clozapine and ziprasidone, while the low activity counts of the rats in the haloperidol group remained unchanged over the test period. This corroborates earlier studies ${ }^{31,42,43}$ showing a reduced activity under haloperidol application closely related to the mesolimbic and mesocortical nervous system. Sorge ${ }^{44}$ also showed that clozapine had no effect on the spontaneous locomotor activity of rats.

Antagonistic blockade of dopamine D2 receptors using haloperidol led to a suppression of locomotor activity in rats by decreasing the excitability of the spinal motor centers. ${ }^{45}$ The study of Huang et al. ${ }^{46}$ found that locomotion and appetitive behavior are differently sensitive to haloperidol, which allows the suggestion that separable D2 mechanisms are involved in regulating the feeding behavior. Nitric oxide seems to play a role not only in drinking regulation but also in motor behavior, probably due to interference with dopaminergic neurotransmission. ${ }^{47}$ Decreased water consumption can cause tiredness, obnubilation, and apathy in humans. Both systems and their interaction may explain the very low activity level in male rats under haloperidol medication. The reduced activity under haloperidol was not solely induced by a dysfunction of water balance - in animals treated with ziprasidone there was reduced water consumption, but no decreased locomotor activity was detectable despite the high affinity of this drug to bind to dopamine D2 and D3 receptors.

\section{Serum leptin level and receptor expression in the hypothalamus}

Clozapine and olanzapine seem to cause the greatest risk of weight gain for respectively treated patients, whereas ziprasidone or haloperidol generally account for no or minimal increase in weight. ${ }^{48}$ As shown by Atmaca et al., ${ }^{4}$ leptin is involved in the regulation of body weight, and its concentration in blood seems to be increased under clozapine medication. However, Haupt et al. ${ }^{17}$ found no differences in plasma leptin concentrations calculated separately according to gender and concluded that the increased weight under antipsychotic medication was not correlated with a malfunctioning leptin secretion or sensitivity, respectively. Kraus et al. ${ }^{49}$ measured lower leptin levels in schizophrenics compared to depressive patients. He found that the decreased leptin concentration was independent of drug medication.

Our results showing a lower serum leptin level after a 6week treatment with haloperidol were similar to the findings of Minet-Ringuet et al. ${ }^{32}$ Except for the clozapine and ziprasidone groups at the time of the first blood sampling after 2 weeks of drug application, we found no changes in the leptin blood concentration among the four groups of animals, although animals medicated with haloperidol exhibited decreased body weight. Therefore, we conclude that the drugs have no effect on the leptin secretion of the adipocytes. We had the same results as Hauner et al., ${ }^{50}$ finding no in vitro effect of clozapine on leptin expression and its release from the adipocytes. In line with these findings, Minet-Ringuet et al. ${ }^{41}$ reported that haloperidol had no effect on cell size, lipolytic activity, and glucose transport activity in rat adipocytes after a five-week oral treatment.

Animal models do not always mimic clinical findings but can help researchers understand underlying mechanisms. Due to metabolic differences between humans and rodents, our model naturally has its limits. One of them is the finding of the applied drugs having no effect on serum leptin levels in male Wistar rats, which seem to be less sensitive to druginduced metabolic changes than Sprague Dawley ${ }^{32}$ or Han Wistar rats. ${ }^{21}$ Both of the named rat strains showed druginduced differences in serum leptin levels.

Because we lacked specifications, we chose drug doses corresponding to the results of the preliminary dose test. Jennings et al. ${ }^{51}$ showed that the increased c-Fos expression in the rat brain induced by oral administration of $10 \mathrm{mg} / \mathrm{kg}$ ziprasidone may be consistent with reported clinical effects. In human patients, the chosen dose of ziprasidone is normally 10 times higher than the haloperidol dose. However, lacking data on the antipsychotic efficacy in our rat model is a strong limitation of our study. Furthermore, our treatment period may have been too short to show significant alterations in leptin levels, and studies using long-term treatment are recommended.

Leptin plays a significant role in energy homeostasis. ${ }^{52}$ It signals the status of fat stores to the hypothalamus and interacts with orexigenic and anorexigenic central pathways. Strong receptor expression was demonstrated in regions of the hypothalamus. ${ }^{53}$ Leptin receptors expressed in hypothalamic areas process the intensity of the leptin signal and effector systems, including the sympathetic nervous system, and supervise energy intake and expenditure.

Although food and water consumption was significantly decreased in rats medicated with haloperidol and ziprasidone compared to controls, we found no changes in hypothalamic leptin receptor expression, even after prolonged antipsychotic drug medication. Liu et al. ${ }^{54}$ found that the blood concentration of leptin in obese rats was increased and that gene expression levels of $\mathrm{Ob}-\mathrm{Ra}$ and $\mathrm{Ob}-$ $\mathrm{Rb}$ in the hypothalamus were significantly reduced. Leptin blood concentration in obese rats had a significant negative association with both $\mathrm{Ob}-\mathrm{Ra}$ and $\mathrm{Ob}-\mathrm{Rb}$ gene expression levels in the hypothalamus, and this suggests that a leptin mediated down-regulation of $\mathrm{Ob}-\mathrm{R}$ expression is one of the 
leptin-resistant mechanisms for maintaining obesity. In summary, the results of our study suggest that the atypical antipsychotic drugs clozapine and ziprasidone do not influence the peripheral and central pathway of leptin in Wistar rats. It is plausible that these drugs have a direct effect on the rat brain, especially mediated by NPYcontaining neurons of the hypothalamus. ${ }^{55}$ Oral antipsychotic treatment with these drugs did not cause weight gain in male rats. This finding is concordant with the results of Baptista et al. ${ }^{55}$ who found no conclusive evidence that leptin was involved in inducing obesity in patients after atypical antipsychotic drug medication.

\section{ACKNOWLEDGMENTS}

We thank Dr. A. Treiber, director of the TVA, Heinrich-HeineUniversität, Düsseldorf, and her assistants for excellent support regarding the animal experiments. Dr. M. Jänner, Rheinische Kliniken, Düsseldorf, kindly shared her expertise in the statistical analysis of our results.

\section{REFERENCES}

1. Allison DB, Mentore JL, Heo M, Chandler LP, Cappellari JC, Infante MC, Weiden PJ. Antipsychotic-induced weight gain: A comprehensive research synthesis. Am J Psychiatry. 1999;156: 1686-96.

2. Covell NH, Weissman EM, Essock SM. Weight gain with clozapine compared to first generation antisychotic medications. Schizophr Bull. 2004;30:229-40.

3. Warrington L, Lombardo I, Loebel A, Ice K. Ziprasidone for the treatment of acute manic or mixed episodes associated with bipolar disorder. CNS Drugs. 2007;21:835-49, doi: 10.2165/00023210-20072110000004 .

4. Atmaca M, Kuloglu M, Tezcan E, Ustundag B. Serum leptin and triglyceride levels in patients on treatment with atypical antipsychotics. J Clin Psychiatry. 2003;64:598-604, doi: 10.4088/JCP.v64n0516.

5. Theisen FM, Linden A, König IR, Martin M, Remschmidt H, Hebebrand J. Spectrum of binge eating symptomatology in patients treated with clozapine and olanzapine. J Neural Transm. 2003;110: 111-21.

6. Kluge M, Schuld A, Himmerich H, Dalal M, Schacht A, Wehmeier PM et al. Clozapine and olanzapine are associated with food craving and binge eating: results from a randomized double.blind study. J Clin Psychopharmacol. 2007;27:662-6, doi: 10.1097/jcp.0b013e31815a8872.

7. Weston-Greene K, Huang XF, Han M, Deng C. The effects of antipsychotics on density of cannabinoid receptors in the dorsal vagal complex of rats: implications for olanzapine-induced weight gain. Int J Neuropsychopharmacol. 2008;11:827-35.

8. Houseknecht KL, Baile CA, Matteri RL, Spurlock ME. The biology of leptin; a review. J Animal Sci. 1998;76:1405-20.

9. Cancello R, Tounian A, Poitou $\mathrm{CH}$, Clément K. Adiposity signals, genetics and body weight regulation in humans. Diabetes Metab. 2004;30:215-27, doi: 10.1016/S1262-3636(07)70112-X

10. Chehab FF, Qiu J, Ogus S. The use of animal models to dissect the biology of leptin. Recent Prog Horm Res. 2004;59:245-66, doi: 10.1210/rp. 59.1.245.

11. Dhillo WS. Appetite regulation: an overview. Thyroid. 2007;17: 433-45, doi: 10.1089/thy.2007.0018.

12. Funahashi H, Yada T, Suzuki R, Shioda S. Distribution, function and properties of leptin receptors in the brain. Int Rev Cytology. 2003; 224:127, doi: 10.1016/S0074-7696(05)24001-9.

13. Kirk SL, Glazebrook J, Grayson B, Neill JC, Reynolds GP: Olanzapineinduced weight gain in the rat: role of 5 -HT2C and histamine H1 receptors. Psychopharmacology. 2009;207:119-25, doi: 10.1007/s00213009-1639-8.

14. Deng C, Weston-Green K, Huang XF: The role of histaminergic H1 and $\mathrm{H} 3$ receptors in food intake: a mechanism for atypical antipsychoticinduced weight gain? Prog Neuropsycho-pharmacol Biol Psychiatry. 2010;34:1-4, doi: 10.1016/j.pnpbp.2009.11.009.

15. Hägg S, Söderburg S, Ahrén B, Olsson $T$, Mjörndal T. Leptin concentrations are increased in subjects treated with clozapine or conventional antipsychotics. J Clin Psychiatry. 2001;62:843-8, doi: 10. 4088/JCP.v62n1102

16. Arranz B, Rosel P, Ramirez N, Duenas R, Fernandez P, Sanchez JM et al. Insulin resistance and increased leptin concentrations in noncompliant schizophrenia patients but not in antipsychotic-naive first-episode schizophrenia patients. J Clin Psychiatry. 2004; 65:1335-42, doi: 10. 4088/JCP.v65n1007.

17. Haupt DW, Luber A, Maeda J, Melson AK, Schweiger DA, Newcomer JW. Plasma leptin and adiposity during antipsychotic treatment of schizophrenia. Neuropsychopharmacol. 2005;30:184-91, doi: 10.1038/sj. npp.1300563.

18. Thakore JH, Mann JN, Vlahos I, Martin A, Reznek R. Increased visceral fat distribution in drug-naive and drug-free patients with schizophrenia. Int J Obes. 2002;26:137-41, doi: 10.1038/sj.ijo.0801840.

19. McIntyre RS, Mancini DA, Basile VS, Srinivasan J, Kennedy SH. Mechanisms of antipsychotic-induced weight gain. J Clin Psychiatry. 2001;62(suppl 23):23-9.

20. Minet-Ringuet J, Even PC, Goubern M, Tomé D, de Beaurepaire R. Long term treatment with olanzapine mixed with the food in male rats induces body fat deposition with no increase in body weight and no thermogenic alteration. Appetite. 2006;46:254-62, doi: 10.1016/j.appet.2006.01.008.

21. Cooper GD, Harrold JA, Halford JCG, Goudie AJ. Chronic clozapine treatment in female rats does not induce weight gain or metabolic abnormalities but enhances adiposity: Implications for animal models of antipsychotic-induced weight gain. Prog Neuropsychopharmacol Biol Psychiatry. 2008;32:428-36, doi: 10.1016/j.pnpbp.2007.09.012.

22. Kapur S, Wadenberg ML, Remington G. Are animal studies of antipsychotics appropriately dosed? Lessons from the bedside to the bench. Can J Psychiatry. 2000;45:241-6.

23. Sprick U, von Wilmsdorff M, Bouvier ML, Gaebel W. Behavioral and hippocampal changes after prenatal invasive interventions with possible relevance to schizophrenia. Behav Brain Res. 2006;172: 179-86, doi: 10. 1016/j.bbr.2006.03.014.

24. Madiehe AM, Schaffhauser AO, Braymer DH, Bray G, York DA. Differential expression of leptin receptor in high- and low-fat OsborneMendel and S5B/PI rats. Obesity Res. 2000;8:467-74, doi: 10.1038/oby. 2000.58.

25. Pillai A, Parikh V, Terry jr AV, Mahadik SP. Long-term antipsychotic treatments and crossover studies in rats: differential effects of typical and atypical agents on the expression of antioxidant enzymes and membrane lipid peroxidation in rat brains. J Psychiatric Res 2007;41:372-86, doi: 10. 1016/j.jpsychires.2006.01.011.

26. Sharpe JK, Stedman TJ, Byrne NM, Wishart C, Hills AP. Energy expenditure and physical activity in clozapine use: implications for weight management. Aust N Z J Psychiatry. 2006;40:810-4.

27. Cooper GD, Harrold JA, Halford JC, Goudie AJ. Chronic clozapine treatment in female rats does not induce weight gain or metabolic abnormalities but enhance adiposity: implications for animal models of antipsychotic-induced weight gain. Prog Neuropsychopharmacol Biol Psychiatry. 2008;32:428-36, doi: 10.1016/j.pnpbp.2007.09.012.

28. Schmitt A, Zink M, Müller B, May B, Herb A, Jatzko A, et al. Effects of long-term antipsychotic treatment on NMDA receptor binding and gene expression of subunits. Neurochem Res. 2003;28:235-41, doi: 10.1023/ A:1022325116309.

29. Albaugh VL, Henry CR, Bello NT, Hajnal A, Lynch SL, Halle B, et al. Hormonal and metabolic effects of olanzapine and clozapine related to body weight in rodents. Obesity. 2006;14:36-51, doi: 10.1038/oby.2006.6

30. Hartfield AW, Moore NA, Clifton PG. Effects of clozapine, olanzapine and haloperidol on the microstructure of ingestive behaviour in the rat. Psychopharmacology. 2003;167:115-22.

31. Yoshida H, Itsukaichi O, Saito H, Masuda Y, Itoh T. Toxicological study on rats fed haloperidol: 80 week chronic toxicity test. J Tox Sci. 1995;20:37-46

32. Minet-Ringuet J, Even PC, Guesdon B, Tomé D, de Beaurepaire R. Effects of chronic neuroleptic treatments on nutrient selection, body weight and body composition in the male rat under dietary self-selection. Behav Brain Res. 2005;163:204-11, doi: 10.1016/j.bbr.2005.05.004.

33. Lee MD and Clifton PG. Meal patterns of free feeding rats treated with clozapine, olanzapine or haloperidol. Pharmacol Biochem Behav. 2002;71:147-54, doi: 10.1016/S0091-3057(01)00630-X.

34. Sanci V, Houle S, da Silva JN. No change in dopamine D1 receptor in vivo binding in rats after sub-chronic haloperidol treatment. Can J Physiol Pharmacol. 2002;80:36-41, doi: 10.1139/y02-002.

35. Davoodi N, Kalinichev M, Clifton PG. Comparative effects of olanzapine and ziprasidone on hypophagia enhanced by histamine neurotransmission in the rat. Behav Pharmacol. 2008;19:121-8, doi: 10.1097/FBP. 0b013e3282f62c66.

36. Fell M, Neill J, Anjum N, Peltola L, Marshall K. Investigation into the influence of a high fat diet on antipsychotic.induced weight gain in female rats. J Psychopharmacol. 2008;22:182-6, doi: 10.1177/ 0269881107082287.

37. Terry AV, Hill WD, Parikh V, Waller JL, Evans DR, Mahadik SP. Differential effects of haloperidol, risperidone, and clozapine exposure on cholinergic markers and spatial learning performance in rats. Neuropsychopharmacology. 2003;28:300-9, doi: 10.1038/sj.npp.1300039.

38. Calapai G, Caputi AP. Nitric oxide and drinking behaviour. Regul Pept. 1996;66:117-21, doi: 10.1016/0167-0115(96)00050-X.

39. Calapai G, Corica F, Allegra A, Corsonello A, Sautebin L, De Gregorio T, et al. Effects of intracerebroventricular leptin administration on food intake, body weight gain and diencephalic nitric oxide synthase activity in the mouse. Br J Pharmacol. 1998;125:798-802, doi: 10.1038/sj.bjp. 0702121. 
Animal model of antipsychotics and leptin

CLINICS 2010;65(9):885-894

vo Wilmsdorff $\mathrm{M}$ et al.

40. Yang SJ and Denbow DM. Interaction of leptin and nitric oxide on food intake in broilers and leghorns. Physiol Behave. 2007;92:651-7, doa: 10. 1016/j.physbeh.2007.05.009.

41. Mint Ringuet J, Even PC, Valet P, Carpéné C, Visentin V, Prévot D, et al. Alterations of lipid metabolism and gene expression in rat adipocytes during chronic olanzapine treatment. Mol Psychiatry. 2007;12:562-71, di: $10.1038 /$ sj.mp.4001948.

42. Fischer V, Schmitt U, Weigmann H, v Keller B, Rus S, Hiemke C, et al. Chronical haloperidol and clozapine treatment in rats: differential RNA display analysis, behavioural studies and serum level determination. Prog Neuropsychopharmacol Biol Psychiatry. 1998;22:1129-39, doi: 10. 1016/S0278-5846(98)00065-7.

43. Schmitt U, Dahmen N, Fischer V, Weigmann H, Roo ML, Rus S, et al. Chronic oral haloperidol and clozapine in rats: a behavioural evaluation. Neuropsychobiol. 1999;39:86-91, doi: 10.1159/000026566.

44. Sorge S. Der Einfluss de atypischen Neuroleptikums Clozapin au dos Verhalten ind dos Immunsystem der Rote. Dissertation, München 2003.

45. Zvezdochkina NV, Muranova LN, Andrianov SS, Gainutdinov KhL, Golubev Al. Locomotor responses and neuron excitability in conditions of haloperidol blockade of dopamine in invertebrates and vertebrates. Neurosci Behav Physiol 2006;36:21-7.

46. Huang AC, Shy BC, Hsiao S. Dose-dependent dissociable effects of haloperidol on locomotion, appetitive responses, and consummatory behavior in water-deprived rats. Pharmacol Biochem Behave 2010; 95: 285-91.

47. Del Bel EA, Guimarães FS, Bermúdez-Echeverry M, Goes MZ, Schiaveto-de-souza A, Padovan-Neto FE, et al. Role of nitric oxide on motor behavior. Cell Mol Neurobiol. 2005;25:371-92, do: 10.1007/s10571005-3065-8.

48. Newcomer JW. Second-generation (atypical) antipsychotics and metabolic effects: a comprehensive literature review. CNS Drugs. 2005; 19 Suppl1:1-93.

49. Kraus T, Hack M, Schuld A, Hinze-Selch D, Kühn M, Ukr M, et al. Body weight and leptin plasma levels during treatment with antipsychotic drugs. Am J Psychiatry. 1999;156:312-14.

50. Hauner H, Röhrig K, Hebebrand J, Skunk Th. No evidence for a direct effect of clozapine on fat-cell formation and production of leptin and other fat-cell-derived factors. Mol Psychiatry. 2003;8:258-59, dor: 10. 1038 /sj.mp.4001246.

51. Jennings CA, Cluderay JE, Gartlon J, Cilia J, Lloyd A, Jones DN, et al. The effects of ziprasidone on regional c-Fos expression in the rat forebrain. Psychopharmacology. 2006;184:13-20, dor: 10.1007/s00213-005-0222-1.

52. Jéquier E. Leptin signalling, adiposity, and energy balance. Ann NY Accad Sci. 2002;967:379-88, do: 10.1111/j.1749-6632.2002.tb04293.x.

53. Trayhurn $P$ and Being C. Appetite and energy balance signals from adjpocytes. Phil Trans R Soc. 2006;361:1237-49, doc: 10.1098/rstb.2006.1859.

54. recept J ian J, Endoh A. Obesity reduced the gene expressions of leptin doa: $10.1055 / \mathrm{s}-2007-981680$.

55. Reynolds GP, Hill MJ, Kirk SL. The 5-HT2c receptor and antipsychoticinduced weight gain-mechanisms and genetics. J Psychopharm. 2006;20:15-8, dor: 10.1177/1359786806066040.

56. Baptists $\mathrm{T}$ and Beaulieu S. Are leptin and cytokines involved in body weight gain during treatment with antipsychotic drugs? Can J Psychiatry. 2002;47:742-9.

894 